DOI: https://DOI.ORG/10.25146/2587-7844-2021-16-4-89

\title{
УДК 808.2-5(075.8)
}

\section{ЗНАЧЕНИЕ МОРФОЛОГИЧЕСКИХ РАЗЛИЧИЙ ПРИ ОБУЧЕНИИ МОНГОЛОВ РУССКОЙ ГРАММАТИКЕ}

\section{И.В. Бойко (Иркутск, Россия)}

\section{Аннотация}

Постановка проблемы. Русский и монгольский языки неродственные, разноструктурные, отличающиеся друг от друга во всех лингвистических аспектах, прежде всего грамматики, однако, к сожалению, до сих пор отсутствует их системное сопоставительное описание. К тому же русский язык из обязательного для изучения (во всех школах и вузах) иностранного языка, каким он был раньше, стал изучаться только в 7-9-х классах общеобразовательных школ. Все это отрицательно сказывается на подготовке учителей-русистов, у многих из которых недостаточно сформированы лингвистическая и речевая компетенции, поэтому, по нашему представлению, следует усовершенствовать подход к преподаванию русской грамматики в монгольской аудитории.

Цель статьи - на основе сопоставительной характеристики глаголов и имен существительных спрогнозировать наиболее острые зоны интерференции в построении синтаксических структур и помочь избежать отрицательного взаимовлияния.

Результаты исследования. В работе представлена системная сопоставительная характеристика морфологических категорий существительных и глаголов в русском и монгольском языках, сделанная автором на основе исследований С. Галсана и Ц. Цэдэндамбы.

Bblводы. В результате определяются основные зоны интерференции. Это, во-первых, структурное несовпадение русских односоставных предложений с их монгольскими эквивалентами и, во-вторых, синтаксические модели с детерминантами вообще и с субъектнообъектными в частности. Знание этого позволит учителю при планировании уделять больше времени данным структурам, последовательной непрекращающейся работе с ними, что в итоге поможет формированию лингвистической, речевой и коммуникативной компетенций.

Ключевые слова: морфологические категории, сопоставительное описание языков, речевой образеи, синтаксическая модель, субъектный детерминант, субъектно-объектный детерминант, лингвистическая, речевая и коммуникативная компетенции.

остановка проблемы. В XX в. русский язык в Монголии был обязательным для изучения в средней общеобразовательной школе и во всех высших учебных заведениях, его знали практически все. Однако в настоящее время он утратил свои позиции и изучается лишь в 7-9-х классах. Сократилась и потребность в квалифицированных специалистах по русскому языку как иностранному; учителям рекомендовалось «переориентироваться» на английский, в результате чего снизился уровень подготовки учителей-русистов и значительно уменьшилось количество людей, говорящих на русском языке. В этом нас убедила работа на курсах повышения квалификации по русскому языку как иностранному для монгольских учителей-словесников и на занятиях с учащимися 
7-12-х классов, выполняемая Иркутским государственным университетом в рамках грантовых программ фонда «Русский мир».

Обзор научной литературы. К сожалению, до сих пор нет полного системного сопоставительного описания русского и монгольского языков. В 40-70-е гг. ХХ в. появились исследования по изучению монгольского (бурят-монгольского) языка [Бертагаев, 1964; Санжеев, 1940], а также работы по компаративной характеристике названных языков [Галсан, 1975; Цэдэндамба, 1974; 1978], но этого недостаточно для успешного изучения русского как иностранного. К тому же в настоящее время, насколько нам известно, не ведутся исследования по синтаксису монгольского языка с учетом достижений современной лингвистики, тогда как знание основных синтаксических моделей предикативных единиц и умение применять их на практике говорит о формировании всех видов компетенций: языковой, речевой и коммуникативной. Осознанное же овладение речевыми образцами - синтаксическими моделями, считаем, невозможно без умения сопоставлять как грамматическую систему родного языка обучающихся, так и систему изучаемого языка (в нашем случае монгольского и русского). Эти знания и умения необходимы прежде всего преподавателю русского языка как иностранного, работающего в современной монгольской школе; в противном случае, как нам кажется, статус русского языка в этой стране еще более понизится. На наш взгляд, необходимо усовершенствовать подход к преподаванию русской грамматики в монгольской аудитории.

В связи с этим цуель нашей статьи - на основе сопоставительной характеристики глаголов и имен существительных спрогнозировать наиболее острые зоны интерференции в построении синтаксических структур и помочь избежать их отрицательного взаимовлияния. Зоны интерференции трактуем как весь ареал грамматических конструкций в изучаемом языке, не имеющих эквивалентных построений в родном и поэтому являющихся объектом потенциального отрицательного взаимодействия. Так, поскольку в монгольском языке нет слов категории состояния, можно констатировать, что любые русские синтаксические модели, в которых есть названная морфологическая форма, будут трудными для монголов. Следовательно, необходимо учитывать этот факт в практике преподавания русского языка как иностранного в монгольской среде.

Результаты исследования. Общеизвестно, что основным принципом преподавания грамматики иностранцам является представление лингвистического явления в контексте: в словосочетании или предложении. В статье мы остановимся на введении в активную речевую практику простых предикативных конструкций, а «строительным материалом» для них в сопоставляемых языках служат морфологические формы. Для сравнения мы представим не все морфологические средства, а только те, которым в любом языке отводится роль синтаксических инструментов и которые выполняют функции субъекта, предиката и модификаторов в простом неосложненном предложении.

Функции субъекта и предиката в обоих языках преимущественно выполняют существительное и глагол. 
В лингвистике понятие модификатор дискуссионно, косвенным свидетельством чему является отсутствие толкования термина в современных словарях.

Мы понимаем под модификатором непредикативную синтаксическую конструкцию, выполняющую роль смыслового конкретизатора либо распространителя предикативной основы, манифестирующего конкретную синтаксическую функцию.

В русском языке модификаторами могут быть как самостоятельные падежные словоформы, так и словоформы в сочетании с предлогами, роль которых заключается в выражении смысловых отношений между ними. Предлоги тесно связаны с категорией падежа. В монгольском же языке «нет предлогов. Связь между словами и словосочетаниями в предложениях в основном осуществляется посредством падежных аффиксов и послелогов» [Цэдэндамба, 1978, с. 124]. Монгольские послелоги в основном эквивалентны русским предлогам [Галсан, 1975, с. 274-286; Цэдэндамба, 1978, с. 123-127], то есть так же, как предлоги в русском языке, конкретизируют синтаксическую функцию непредикативных второстепенных членов предложения.

Сравним морфологические категории имен существительных в сопоставляемых языках.

Таблица 1

\section{Сопоставление морфологических категорий имен существительных в русском и монгольском языках}

Table 1

Noun Morphological Category Comparison in the Russian and Mongolian languages

\begin{tabular}{|c|c|c|}
\hline Грамматические категории & Русский язык & Монгольский язык \\
\hline $\begin{array}{l}\text { Категория одушевленности / } \\
\text { неодушевленности }\end{array}$ & Имеется & Отсутствует [Галсан, 1975, с. 120] \\
\hline Категория рода & $\begin{array}{l}\text { Мужской } \\
\text { Женский } \\
\text { Средний }\end{array}$ & Отсутствует [Галсан, 1975, с. 120] \\
\hline Категория числа & $\begin{array}{l}\text { Единственное } \\
\text { Множественное }\end{array}$ & $\begin{array}{l}\text { Нуждается в специальном иссле- } \\
\text { довании [Галсан, 1975, с. 129] }\end{array}$ \\
\hline Категория падежа & $\begin{array}{l}6 \text { падежей: именительный, } \\
\text { родительный, дательный, } \\
\text { винительный, творитель- } \\
\text { ный, предложный }\end{array}$ & $\begin{array}{l}8 \text { падежей: именительный, роди- } \\
\text { тельный, дательно-местный, ви- } \\
\text { нительный, исходный, творитель- } \\
\text { ный, направительный, совместный } \\
\text { [Галсан, 1975, с. 130-148; Цэдэн- } \\
\text { дамба, 1974, с. 28-49] }\end{array}$ \\
\hline
\end{tabular}

Из приведенных данных видно, что в основном морфологические категории существительных в сопоставляемых языках не совпадают.

Отсутствие грамматической категории рода существительных в монгольском языке и неопределенность в обозначении грамматической формы числа означают, что при построении русского предложения потенциальны ошибки в следующих ситуациях: 1) согласование в формах рода, числа и падежа; 2) склонение. 
Отметим, что синтаксической связи согласования в монгольском языке нет [Цэдэндамба, 1978, с. 14]. Следовательно, необходимо использовать как можно больше упражнений на отработку моделей «прилагательное + существительное». Методисты знают: чтобы грамматическое явление было усвоено и был выработан навык в его употреблении, нужно повторение его не менее 15-25 раз [Акишина, Каган, 2004].

Несмотря на то что названия пяти из восьми монгольских падежей совпадают с русскими, семантическое содержание их в большинстве случаев различно. Так, например, в русском языке существительным в родительном падеже со значением качественной семантики (Это был мальчик семи лет; человек высокого роста) соответствует монгольская форма совместного падежа (Долооннастай жаал (буквально: семь с возрастом мальчик); Өндөрнуруутай хун (буквально: высокий с ростом человек) [Галсан, 1975, с. 142].

Еще один пример. В русском языке при обозначении живых существ, лиц при переходных глаголах употребляется форма винительного падежа имени существительного: читать книгу; поздравлять бабушку; любить сестру. В монгольском же языке из-за отсутствия грамматической категории рода формы винительного падежа совпадают с формами родительного, за исключением сочетаний с глаголами любить и поздравлять, которые требуют после себя дательноместного падежа (типа Поздравляю вам, любить нам) [Галсан, 1975, с. 147].

Особый интерес для нас представляет тот факт, что русской словоформе в дательном падеже «при предикативных наречиях и безличных глаголах... никогда нет соответствия» [Галсан, 1975, с. 145]. Причину этого определим в ходе дальнейшего исследования.

Обратимся к сравнению глаголов, представляя их грамматические характеристики в таблице. (Мы намеренно не останавливаемся в этой работе на их формах - деепричастии и причастии, которым в монгольском языке отводится значительная роль: они могут выступать как знаменательные и служебные части речи и имеют существенное значение в образовании сложных предложений.)

\section{Сопоставление морфологических категорий глаголов в русском и монгольском языках}

Таблица 2

Table 2

Verb Morphological Category Comparison in the Russian and Mongolian languages

\begin{tabular}{|l|l|l|}
\hline Грамматические категории & \multicolumn{1}{|c|}{ Русский язык } & \multicolumn{1}{|c|}{ Монгольский язык } \\
\hline \multicolumn{1}{|c|}{1} & \multicolumn{1}{|c|}{2} & \multicolumn{1}{c|}{3} \\
\hline Вид & $\begin{array}{l}\text { Совершенный } \\
\text { Несовершенный }\end{array}$ & $\begin{array}{l}\text { Отсутствует [Галсан, 1975, с. 203; Цэ- } \\
\text { дэндамба, 1974, с. 80] }\end{array}$ \\
\hline Время & $\begin{array}{l}\text { Настоящее } \\
\text { Прошедшее }\end{array}$ & $\begin{array}{l}\text { Настоящее } \\
\text { Прошедшее (давнопрошедшее } \\
\text { недавнопрошедшее) } \\
\text { Будущее [Галсан, 1975, с. 209-217] }\end{array}$ \\
\hline
\end{tabular}


Окончание табл. 2

\begin{tabular}{|c|c|c|}
\hline 1 & 2 & 3 \\
\hline Наклонение & $\begin{array}{l}\text { Изъявительное } \\
\text { Повелительное } \\
\text { Сослагательное }\end{array}$ & $\begin{array}{l}\text { Изъявительное } \\
\text { Повелительно-желательное: со значе- } \\
\text { ниями побуждения, просьбы, предо- } \\
\text { стережения, напоминания, опасения } \\
\text { Отсутствует [Галсан, 1975, с. } 223 \text { ] }\end{array}$ \\
\hline Залог & $\begin{array}{l}\text { Действительный } \\
\text { Страдательный }\end{array}$ & $\begin{array}{l}\text { Прямой } \\
\text { Страдательный } \\
\text { Побудительный } \\
\text { Совместный } \\
\text { Взаимный [Галсан, 1975, с. 224-227] }\end{array}$ \\
\hline Число & $\begin{array}{l}\text { Единственное } \\
\text { Множественное }\end{array}$ & Отсутствует [Галсан, 1975 с. 197-203] \\
\hline Лицо & 1 л., 2 л., 3 л. & Отсутствует [Галсан, 1975, с. 197-203] \\
\hline Род & $\begin{array}{l}\text { У глаголов в форме } \\
\text { прошедшего времени } \\
\text { (муж., жен., сред. р.) }\end{array}$ & Отсутствует [Галсан, 1975, с. 197-203] \\
\hline
\end{tabular}

Таким образом, мы имеем несовпадения во многих глагольных категориях, что служит потенциальным показателем интерференции, или влияния родного языка на изучаемый, при построении предложений, в которых глагол выполняет роль предиката. Не случайно Ц. Цэдэндамба отмечал невозможность структурного совпадения многих русских предикативных конструкций с монгольскими [1978, с. 13]. Прежде всего это касается образования односоставных предложений, соотносительных с русскими глагольно-личными и безличными, чему есть объяснение: в качестве средства выражения главных членов в русских односоставных предложениях выступают глаголы с показателями определенных морфологических категорий. Так, например, в безличных структурах главный член может быть выражен либо глаголом в форме 3 лица настоящего / будущего времени, либо в форме прошедшего времени единственного числа среднего рода, либо словами категории состояния. В монгольском же языке, как уже говорилось, вопрос о грамматическом числе и грамматическом роде у глаголов и существительных до сих пор является предметом дискуссий и разногласий [Галсан, 1975; Цэдэндамба, 1978]. Слова категории состояния в монгольской грамматике также отсутствуют [Галсан, 1975, c. 201-202]. И именно в этих синтаксических группах имеется больше всего нарушений, выражающихся в незнании речевых образцов типа Я нравится, У них еще трудно; Ей что-то случилось [Бойко, 2017, с. 101-102].

Смысловое содержание русских безличных предложений выражается в монгольском языке иными - двусоставными предикативными структурами, например:

1) Сегодня на улице холодно - Оноордор гадаа хуйтэн байна - досл.: Сегодняшний день холод есть;

2) Ему скучно - Тэр уйтгартай байна - досл.: Он скука есть;

3) Мне не хочется ехать в гости - Би зочиллохыг хусэхгуй байна - досл.: Я гости не хочу быть; 
4) У нас нет билетов в театр - Бидэнд театр явах билет байхгуй - досл.: Mbl театр ехать билет не имеем.

Двусоставные эти структуры потому, что, как мы полагаем, в монгольском языке не может быть предложений без подлежащего, занимающего препозицию в предложении, и сказуемого, стоящего в абсолютном конце синтаксической конструкции. Наблюдается взаимозависимость между жесткой конструкцией структурной схемы монгольского простого предложения и синтаксической ролью членов этой схемы, которые определяются их морфологическими свойствами.

Как видим, хотя перевод транслирует основное содержание, все же он не передает основную семантику безличных предложений - отсутствие активного деятеля или носителя признака, о чем свидетельствует сама форма главного члена, не допускающая грамматического подлежащего - имени существительного или местоимения в именительном падеже.

Особенно трудны для монголов безличные структуры, включающие в свой состав слова категории состояния и отрицание, так как в монгольском языке при отрицании требуется именительный падеж: Kнига нет; Maмa нет [Цэдэндамба, 1978 , с. 30]. Следовательно, надо уделить серьезное внимание отработке модели «Нет + имя в род. п./ Нет $\mathrm{N}_{2} »$.

Остановимся более подробно на структурах со словами категории состояния, потому что, как уже отмечалось, их нет в монгольском языке. Однако уже в 7-м классе (IV четверть) при изучении лексической темы «Окружающая среда. Какая сегодня погода?» от ребят требуется знать слова жарко, холодно, тепло, прохладно в сочетании с темпоральными распространителями сегодня, вчера, завтра и уметь употреблять их в речи [Русский язык VII, 2017]. И учащиеся неплохо усваивают названные структуры.

Трудности появляются, когда в предложении имеется детерминант (модификатор), выраженный существительным / местоимением в косвенном падеже или предложно-падежной формой.

В этом случае предлагаем следующий алгоритм работы.

Вначале грамматическая структура (временной детерминант + слово категории состояния / $\mathrm{Adv}_{\text {tempor }}$ Praed) вводится лексически как цельная лексикосинтаксическая единица (Сегодня/вчера/завтра жарко/было/будет) и констатируется, что такая конструкция употребляется в русском языке в ситуации, когда требуется сказать, какая погода.

Затем даются модификации модели с пространственными распространителями (В / На предл. п. - слово категории состояния / В / Ha $\mathrm{N}_{6 \text { locum }}$ Praed) в ее конкретном лексическом воплощении: $B$ городе / на улице... (сегодня) холодно.

По мере изучения языка следует продолжать расширять список лексемраспространителей и слов категории состояния. Рекомендуем завести «Синтаксический словарь», где базовая модель дополняется конкретными лексемами, по возможности указывая их принадлежность к определенной лексико-семантической группе: одушевленное/неодушевленное, собственное/нарицательное существи- 
тельное, личное местоимение, существительное со значением места и др. При этом, на наш взгляд, следует «разводить» омонимичные по способу выражения главного члена структуры с разным семантическим содержанием. Так, например, формы « $\mathrm{N}_{3} /$ Pronom $_{3}$ Praed»: Мне холодно - должны располагаться в другом месте (на другой странице), где будет идти речь об иной семантике, а именно о физическом состоянии человека, независимом от его воли и желания. И здесь будет другой список детерминантов - одушевленных существительных.

Позже, когда будет изучаться тема «Повседневная жизнь. Как ты себя чувствуешь?» (8-й класс, 2-я четверть), будут введены слова плохо, хорошо [Русский язык VIII, 2016]. Предикаты надо/нужно + инфинитив вводятся при изучении темы «Семья. Какие твои обязанности по дому?» (9-й класс, 1-я четверть) [Русский язык IX, 2015].

И лишь на продвинутом этапе обучения можно говорить о психическом состоянии человека и вводить данную структурную модель, наполняя ее другими лексемами: весело, грустно, интересно.

К сожалению, наш опыт работы показывает, что школьные учителя тоже нуждаются в повторении представленного грамматического материала. В их речи встречаются ошибки типа: Учитель надо любить ученики; И мы надо вступить во владение свою профессию; Учитель необходимо быть точным и пунктуальнылм; Мне рады, что вы приехали [Бойко, 2017, с. 102]. Получается, что вроде бы коммуникативная компетенция есть, понимание достигнуто, но речевая и лингвистическая компетенции недостаточно сформированы, а это недопустимо для учителя русского языка как иностранного. Считаем, опираясь на многолетнюю практику преподавания РКИ монгольским учителям-русистам, что и им следует сначала вводить синтаксические модели безличных предложений лексически, чтобы употребление детерминанта в форме дательного падежа было доведено до автоматизма. Предполагаем, что нынешним учителям в период их обучения было предложено толкование этого грамматического явления как дательного субъекта и предложен его двусоставный аналог раньше, чем они научились правильно использовать базовую синтаксическую модель, то есть до формирования у них речевой компетенции.

Повторим, что в случае изучения таких разносистемных, разностуктурных языков, как русский и монгольский, изучаемую грамматическую модель вводят лексически, как единый грамматический комплекс, поясняя, в каких ситуациях это грамматическое явление употребляется. А в дальнейшем учащиеся сами сумеют сделать вывод о глубине лексического и семантического объема данной синтаксической модели.

Приведенные выше примеры с грамматическими искажениями еще раз говорят об актуальности знания морфологических различий сопоставляемых языков и их учета в определении зон интерференции, с тем чтобы при планировании работы уделять структурам, подвергающимся отрицательному взаимовлиянию, особое внимание. 
Рассмотрим еще несколько предикативных структур, которые сложны для монголов, изучающих русский язык. Это модели: 1) «Дат. п. имени - количественноименное сочетание / $\mathrm{N}_{3} \mathrm{~N}_{1}$ » (Мне / брату 17 лет) и 2) «Род. п. имени с предлогом У - имен. п. сущ. / У $\mathrm{N}_{2} \mathrm{~N}_{1} \gg$ (У нее / у сестры (есть) дочь).

Как уже упоминалось, в монгольском языке предикативная структура всегда двусоставна (без сказуемого предложение не оформляется), поэтому и названные синтаксические модели - аналоги русских номинативных предложений с детерминантами - тоже двусоставны. Этим и объясняются грубые грамматические нарушения: Этот раз она 40 лет, то есть у нее было 40 лет [Бойко, 2017, с. 102].

В монгольском языке первой модели соответствует двусоставное предложение, расширенная структурная схема которого имеет такой вид: «Существительное / местоимение в именительном падеже - числительное / количественноименное сочетание - глагол» (досл.: Я 17 лет есть).

Тем не менее знание русской речевой модели необходимо уже на начальном этапе обучения: в 7-м классе (1-я четверть) при изучении темы «Семья. Сколько тебе лет?» [Русский язык VII, 2017]. От учащихся требуется умение употреблять личные местоимения в форме дательного падежа. Рекомендуем сразу же добавить в эту модель названия родственников в форме дательного падежа (брату, отцу, папе, маме, сестре, бабушке, дедушке), а затем личные имена русских (Ивану, Петру, Ольге, Наталье, Ване, Наташе...). Позднее, по мере изучения лексических тем, вносим в список, заполняя «Синтаксический словарь», названия животных (баран, верблюд, конь, собака, овца и др.), городских/деревенских объектов (городу, дворцу, дому, театру, памятнику, деревне, улице и др.). Далее можно распространять детерминанты согласованными определениями (моему брату, старшей сестре...). Иными словами, в рекомендованном «Синтаксическом словаре» синтаксическая модель « $\mathrm{N}_{3} \mathrm{~N}_{1}$ » может быть представлена в таком лексическом воплощении.

Форма дательного падежа

1) мне/я, тебе/mbl, ему/он, ей/она, им/они (личные местоимения);

2) Брату/брат, сестре/сестра, маме/мама, nane/nana...

(одушевленные сущ., названия

родственников);

3) Петру (Петр) / Пете (Петя), Татьяне

(Татьяна) / Тане (Таня); Иванову (Иванов);

Ивановой (Иванова), Надежде Алексеевне

(Надежда Алексеевна), Юрию Сергеевичу

(Юрий Сергеевич), Кузнецуову Ивану

Петровичу (Кузнецьов Иван Петрович),

Симоновой Наталье Владимировне

(Симонова Наталья Владимировна)...

(личные имена);
Количественно-именное сочетание

1) 1-100-1000 (количественные);

2) тылсяча, миллион (сущ.) ЛЕТ;

3) много, мало ЛЕТ(неопределенноколичественные слова) 
4) мальчику/мальчик, девочке/девочка,

дедуике/дедуика... (одушевленные сущ.);

5) верблюду/верблюд, коню/конь,

барану/баран, овиееовиа, собаке/

собака, лошади/лошадь, птице/птица...

(сущ., названия животных, птиц);

6) двориу/дворец, дому/дом,

заводу/завод, театру/mеатр, городу/

город, стране/страна, площзади/площчадь,

зданию/здание (неодушевленные сущ.,

названия городских объектов);

7) моему nanе (мой папа), моей

старией сестре (моя старшая

сестра)... (распространение определениями).

Постоянная планомерная работа приводит к закреплению данной структурной схемы в речи учащихся. Сложнее обстоит дело с моделью «У $\mathrm{N}_{2} \mathrm{~N}_{1}$ » (например: У него ангина), во-первых, потому, что субъектный детерминант в монгольском языке, как и в предыдущей структурной схеме, предстает в форме именительного падежа, и во-вторых, потому, что главный член русского предикативного построения передается разными формами - дательно-местного или совместного - падежей [Цэдэндамба, 1978, с. 18]. Приблизительный перевод может быть таким: Он ангина есть; Он с ангиной есть. Следовательно, и при введении в активную речевую практику этой структурной схемы следует неустанно повторять данную модель, пополняя новыми лексемами (одушевленными существительными - названиями родственников, людей, животных, птиц, личными именами; неодушевленными существительными - названиями объектов и др.).

Названной модели еще и потому следует уделять особое внимание, что детерминант «У $\mathrm{N}_{2}$ » частотен и в других односоставных (безличных) и двусоставных построениях типа: У брата нет дачи; У меня болит голова; У сестры есть машина. Монгольский эквивалент таких предложений в переводе на русский всегда двусоставный: Брат дача нет; Я, который голова болит; Сестра машина есть.

Bblвodbl. В предлагаемой статье мы остановились только на некоторых, на наш взгляд, самых сложных для монголов грамматических явлениях, вызванных интерференцией и легко прогнозируемых при системном учете морфологических различий сопоставляемых языков. Зоны интерференции распространяются, во-первых, на структурное несовпадение русских односоставных предложений с их монгольскими эквивалентами и, во-вторых, на синтаксические модели с детерминантами вообще и с субъектно-объектными в частности. Знание этого позволит учителю при планировании работы уделять больше времени данным структурам, последовательной непрекращающейся работе с ними, что в результате поможет формированию лингвистической, речевой и коммуникативной компетенций. 


\section{Библиографический список}

1. Акишина А.А., Каган О.Е. Учимся учить. Для преподавателя русского языка как иностранного. М.: Рус. яз. Курсы, 2004. 256 с.

2. Бертагаев Т.А. Синтаксис современного монгольского языка в сравнительном освещении. Простое предложение. М., 1964. 279 с.

3. Бойко И.В. Русский язык в современной монгольской школе // Русский язык за рубежом. 2017. № 2. С. 100-105.

4. Галсан С. Сопоставительная грамматика русского и монгольского языков (Фонетика и морфология). Улан-Батор, 1975. Ч. 1. 320 с.

5. Русский язык VII / П. Тунгалаг, И. Мяндас, Р. Бямбадулам и др. Улан-Батор, 2017. 136 с.

6. Русский язык VIII / П. Тунгалаг, Р. Бямбадулам, М. Осохбаяр и др. Улан-Батор, 2016. 168 с.

7. Русский язык IX / П. Тунгалаг, И. Мяндас, О. Туул. Улан-Батор, 2015. 168 с.

8. Санжеев Г.Д. Синтаксис бурят-монгольского языка. Улан-Удэ, 1940. 146 с.

9. Ц Цэдэндамба Ц. Очерки по сопоставительной грамматике русского и монгольского языков. Улан-Батор, 1974. 136 с.

10. Цэдэндамба Ц. Сопоставительный синтаксис русского и монгольского языков. Улан-Батор, 1978. 133 c.

\section{Сведения об авторе}

Бойко Ирина Владимировна - кандидат филологических наук, доцент кафедры филологии и методики педагогического института, Иркутский государственный университет; ORCID: https://orcid.org/; e-mail: iv.boj@mail.ru 


\section{CONSIDERATION OF MORPHOLOGICAL DIFFERENCES IN TEACHING RUSSIAN GRAMMAR TO MONGOLIANS}

\section{I.V. Boyko (Irkutsk, Russia)}

Abstract

Statement of the problem. Russian and Mongolian languages are unrelated, multi-structured, differing from each other in all linguistic aspects, first of all, in grammar. However, unfortunately, their systemic comparative description is still lacking. Besides, the Russian language which used to be compulsory for study as a foreign language in all educational institutions nowadays is studied only in the 7th-9th grades of comprehensive schools. All this negatively affects the Russian language teachers training, many of whom have linguistic and speech competencies insufficiently formed; therefore, in our opinion, the approach to teaching Russian grammar in the Mongolian audience should be improved.

The purpose of the article is as follows: on the basis of the comparative characteristics of verbs, nouns and prepositions, to predict the most acute zones of interference in the construction of syntactic structures and to help avoid negative mutual influence.

As a result, the main areas of interference are determined. This is, firstly, the structural mismatch of Russian one-piece sentences with their Mongolian equivalents and, secondly, syntactic models with determinants in general and with subject-object ones, in particular. Knowing this will allow the teacher, when planning, to devote more time to these structures, consistent continuous work with them, which ultimately will help the formation of linguistic and speech competence.

Keywords: morphological categories, comparative description of languages, speech pattern, syntactic model, subject determinant, subject-object determinant, linguistic, speech and communicative competence.

\section{References}

1. Akishina A.A., Kagan O.E. Uchimsya uchit'. Learning to teach. For a teacher of Russian as a foreign language. M.: Rus. Yaz. Kursy, 2004. 256 p.

2. Bertagaev T.A. The syntax of the modern Mongolian language in comparative coverage. Simple sentence. M., 1964. 279 p.

3. Bojko I.V. The Russian language in the modern Mongolian school // The Russian language abroad]. 2017. No. 2. 279 p.

4. Galsan S. Comparative grammar of the Russian and Mongolian languages (Phonetics and Morphology). Ulan-Bator, 1975. P. 1. 320 p.

5. The Russian language VII / P. Tungalag, I. Myandas, R. Byambadulam et all. Ulan-Bator, 2017. $136 \mathrm{p}$.

6. The Russian language VIII / P. Tungalag, R. Byambadulam, M. Osohbayar et all. Ulan-Bator, 2016. 168 p.

7. The Russian language IX / P. Tungalag, I. Myandas, O. Tuul. Ulan-Bator, 2015. 168 p.

8. Sanzheev G.D. The syntax of the Buryat-Mongolian language. Ulan-Udeh, 1940. 194 p.

9. Cehdehndamba C. Essays on the comparative grammar of the Russian and Mongolian languages. Ulan-Bator, 1978. 136 p.

10. Cehdehndamba C. Comparative syntax of Russian and Mongolian languages. Ulan-Bator, 1978. $133 \mathrm{p}$.

\section{About the author}

Boyko Irina Vladimirovna - PhD (Philology), Associate Professor, Department of Philology and Methodology, Pedagogical Institute of Irkutsk State University (Irkutsk, Russia); ORCID https://orcid.org/; e-mail: iv.boj@mail.ru 